\title{
Electrochemical interaction between graphite and molten salts to produce nanotubes, nanoparticles, graphene and nanodiamonds
}

\author{
Ali Kamali and Derek Fray \\ Department of Materials Science and Metallurgy, University of Cambridge, 27 \\ Charles Babbage Road Cambridge CB3 OFS
}

\begin{abstract}
The electrochemical interaction between graphite and molten salts to produce carbon nanostructures is reviewed. It is demonstrated that, depending on the conditions, it is possible to electrochemically convert graphite in molten salts to either carbon nanoparticles and nanotubes, metal filled carbon nanoparticles and nanotubes, graphene or nanodiamonds. The application of metal filled carbon nanotubes as anodes in lithium ion batteries is reviewed. Surprisingly, this method of preparation is relatively simple and very similar to the mass production of aluminium in molten sodium aluminium fluoride-alumina mixtures, which is performed economically on a tonnage scale, indicating that it may be possible to apply it for the production of novel carbon nanostructures.
\end{abstract}

\section{Introduction}

Molten salts and carbon have contrasting properties in that the former are liquids which conduct electricity mainly by the migration of ions whilst the latter is a solid and can either be an electronic conductor (carbon) or an insulator (diamond), depending on the phase. Carbon can exist in molten salts such as $\mathrm{CO}_{3}{ }^{2-}$ or $\mathrm{C}_{2}{ }^{2-}$ ions or combined with another element to form a gas, $\mathrm{CO}_{2}$ or a hydrocarbon and can also 
exist as an electrode in aqueous or molten salt electrolytes. In the solid state, the electrical conductivity of salts is low due to the lack of defects and the very low diffusion coefficients. On melting, there is usually a significant volume increase (25\%) which indicates significant space in the liquid state and a high diffusion coefficient for the ions leading to a high ionic conductivity coupled with a small electronic conductivity. Application of a voltage to graphite results in a flow of current which is linearly dependent on the applied voltage (Ohm’s law). In comparison, a molten salt will only conduct a significant current above the decomposition potential of the salt which, in turn, leads to its decomposition. At the present time, graphite/carbon is used as electrodes, both anode and cathode, to produce aluminium from alumina dissolved in molten cryolite $\left(\mathrm{Na}_{3} \mathrm{AlF}_{6}\right)$, as the anode in the electrolysis of sodium from molten sodium chloride, magnesium from molten magnesium chloride, lithium from molten lithium chloride and, lastly, the recycling of used nuclear fuel rods using molten lithium chloride [1]. In the Hall-Heroult cell for the production of aluminium, the aluminium ions are discharged on a molten aluminium layer, supported on a graphite cathode, and the oxygen ions are discharged on a carbon anode to form a mixture of carbon dioxide with a small proportion of carbon monoxide [2]. One interesting reaction on the cathode is that sodium is able to codeposit, due to a similar electrode potential to aluminium, and can diffuse to the graphite cathode [3]. For used nuclear fuel rods, the fuel rod is made the cathode in a bath of lithium chloride and the cathodic reaction is ionisation of oxygen in the cathode to give oxygen ions which diffuse through the electrolyte to the anode where discharge takes place to form oxygen on an inert anode (platinum) or a mixture of carbon dioxide and carbon monoxide on a carbon anode [4]. In a totally different field, molten alkali carbonates are used at very elevated temperatures and pressures to 
catalyse the conversion of graphite to diamond [5]. Overall, there is a wealth of information on the interaction of molten salts with carbon which forms the basis of this paper to explore novel and exciting applications.

\section{Interaction of graphite with molten salts}

Molten salts may cause various changes on the structure and microstructure of graphite. The exposure of graphite to molten chloride salts [6,7] will increase the crystallinity degree of the graphite material. The same effect was reported when molten fluoride salts are used, and the effect was attributed to the improvement of stacking order in graphite exposed to molten salts [8]. If graphite and $\mathrm{LiCl}$ are simply heated together to $1250{ }^{\circ} \mathrm{C}$; the graphite tends to break up to form a mixture of exfoliated nanosheets, graphene and nanorods (Figure 1) [7]. It would be an advantage if the graphite could be treated in such a way to get a specific and well defined nanomaterial. At present, this is only achieved on an industrial scale in the conversion of carbon to diamond using a molten metal [9] or molten salt catalyst [10]. In the 1990s, the group of Kroto found that by electrolysing alkali chlorides using a graphite cathode it was possible to create carbon nanotubes [11]. Subsequent work showed that the process involved intercalation and that lithium atoms produced the highest yield of nanotubes whilst the larger alkali atoms, $\mathrm{Na}$ and $\mathrm{K}$, caused the graphite to breakup [12]. It was also found that by using a mixed lithium chloride and tin chloride melt it was possible to obtain carbon nanotubes that were filled with tin and other low melting point metals, depending on the second salt [13].

\section{Effects of varying the microstructure of the graphite and the electrochemical} parameters 
The apparatus for the intercalation of lithium into graphite is shown in Figure 2 [14]. It was found that the structure and morphology of carbon nanomaterials produced were dependent on those of the graphite material used as the cathode in the molten salt process [15]. It was further found that nanoparticles as well as tubes can be formed by changing the temperature of molten salt [6] and the applied cathode current density [16]. The effect of molten salt temperature on the morphology of the carbon product is illustrated in Figures 3 and 4 [14]. However, in the earlier experiments it was observed that the yield of nanotubes and nanoparticles decreased with time and this was interpreted by postulating that the surface of the graphite became saturated with lithium so that instead of the lithium ion discharging and the lithium atoms penetrating the graphite structure, the lithium just formed a layer of lithium metal on the surface of the graphite [17].

It was found that by switching the current every few minutes the generation of nanoparticles and nanotubes continued indefinitely until all the graphite had been consumed [16]. Under these conditions, the lithium continually moved from one electrode to the other and, overall, this had three distinct advantages - first the LiCl was not consumed, which is important in that lithium chloride is expensive, the production of nanotubes and nanoparticles was continuous and the whole rods were, near enough, totally consumed and chlorine evolution was not a problem. In 2014 the scalability of the molten salt process was demonstrated using a modified apparatus [16]. The advantages of the molten salt route for the production of these novel materials is that the process is about 1000 times faster than the catalytic route where a hydrocarbon is dissociated into carbon and hydrogen. The space occupied by the equipment for the molten salt route is very much smaller than that required for the catalytic route as the reactions take place in condensed phases as opposed to a gaseous 
environment. However, the product is slightly different in that the catalytic route produces nanotubes whereas the molten salt route produces nanoscrolls. The mechanism for the production of nanoscrolls and nanoparticles, each containing walls consisting of several layers graphene is the lithium atoms intercalate into the graphite structure causing a strain within the structure which, in turn, encourages the extrusion of graphene sheets. There is a high surface energy between graphite and molten salts so in order to minimise this energy, the sheets roll up to form nanoscrolls and nanoparticles and when tin chloride is present in the salt, the tin can deposit as small droplets on the surface of the graphite around which the graphene sheets can enclose.

\section{Uses of carbon nanoscrolls and nanoparticles}

Both conventional carbon nanotubes and nanoscrolls consist of layers of graphene, it is assumed that the mechanical properties are the same and that the nanoscrolls would find similar applications to those of nanotubes. However, at the present time, although the synthesis of nanoscrolls has been proved in the laboratory, there is no industrial production so that the material is not readily available for evaluation. However, there is one electrochemical application where metal filled carbon nanoscrolls are particularly apposite and that is in lithium-ion batteries. These batteries also use an intercalation process for both anodes and cathodes. Ideally, if a lithium metal anode could be used in the anodic reaction would be

$\mathrm{Li}=\mathrm{Li}^{+}+\mathrm{e}^{-}$

and the cathode reaction is

$\mathrm{Li}^{+}+\mathrm{MeO}_{\mathrm{x}}+\mathrm{e}^{-}=\mathrm{LiMeO}_{\mathrm{x}}$

where $\mathrm{MeO}_{\mathrm{x}}$ is a metal oxide and $\mathrm{LiMeO}_{\mathrm{x}}$ is an intercalation compound in which $\mathrm{Li}$ is mobile and the activity of $\mathrm{Li}$ is very low with the difference in activities between the 
anode and cathode generating the potential to drive the cell [18]. On recharging the cell, the lithium is transferred back to the anode but as it is very difficult to obtain a planar deposit from the electrolyte, the resulting deposit is very dendritic and can grow and contact the cathode, causing a disastrous short circuit leading to fires [19]. In order to overcome this problem, graphite is used as the anode material which can form $\mathrm{Li}_{0.167} \mathrm{C}$ [20]. The activity of the lithium is reduced in this compound which reduces the overall cell voltage slightly but the main problem is the small amount of lithium contained in the anode [20]. However, it can be increased by using Si or Sn as the anode but the compounds, $\mathrm{Li}_{4} \mathrm{Sn}$ and $\mathrm{Li}_{4} \mathrm{Si}$, suffer from the disadvantage of very large volume changes on the addition and removal of lithium cause the anode to decrepitate to very fine particles with little electrical contact with the neighbouring particles [21]. This problem can be overcome by enclosing the tin or silicon inside a carbon nanotube, where the expansion and contraction can be controlled. Tin and silicon have been inserted into carbon nanotubes using the molten salt route described above. The microstructure of tin filled carbon nanoscrolls produced in molten $\mathrm{LiCl}$ is shown in Figure 5 [22]. After carrying out charge-discharge cycles, the cell was dismantled and the anode material was studied by means of transmission electron microscopy [23]. It was deduced that on the first insertion the lithium tin compound formed and caused the nanotube to expand but when the anode discharged the alloy shrank but still remained in contact with the highly conducting carbon nanotube. As it is known that lithium cannot pass through graphene, this must mean that the lithium must move along the sheets of the scroll otherwise passing down the centre of the scroll from the ends would be far too slow. It was found that the capacity of the anode has increased by about $50 \%$ which is encouraging bearing in mind that the anode only contained 50\% of the tin filled carbon nanoscrolls [23]. Using silicon 
filled scrolls instead of tin filled scrolls increased the capacity of the anode considerably [24]. On the other hand, the lack of scalable methods for the preparation of Sn-containing carbon nanostructures is a barrier to the proper evaluation of these nanostructures in an industry where tens of grams are required. However, the molten salt approach was recently demonstrated to be capable of producing large-scale quantities of Sn-containing carbon nanomaterials[25].

\section{Intercalation of hydrogen atoms into graphite to prepare graphene}

It is usually very difficult to get hydrogen molecules to dissolve in graphite or carbon nanotubes. However, it has been shown that it is relatively easy to get lithium to dissolve in graphite and it should be even easier to insert hydrogen atoms into graphite as these atoms are much smaller than the inter layer spacing in graphite. Furthermore, it is known that in comparison to lithium chloride most hydrogen containing compounds such as $\mathrm{H}_{2} \mathrm{O}, \mathrm{HCl}, \mathrm{HBr}$ are far less stable than all lithium compounds and should breakdown under an applied potential before lithium oxide or lithium chloride. Therefore, the presence of water should result in hydrogen atoms intercalating when the graphite, immersed in the molten lithium chloride, is made

cathodic. Experiments showed that under electrochemical intercalation using lithium chloride exposed to argon gas containing water, the graphite is exfoliated into graphene sheets which could then be retrieved simply by washing with water and filtration followed by heating in a reducing atmosphere $\left(15 \% \mathrm{H}_{2}, 85 \% \mathrm{~N}_{2}\right)$ at around $1300^{\circ} \mathrm{C}$ which is above the boiling points of $\mathrm{LiCl}$ and $\mathrm{Li}_{2} \mathrm{CO}_{3}$ [26]. Figure 6 shows the starting and the final graphite rod, showing very even erosion. Figures 7 show a TEM micrograph of the graphene product [26]. The rate of production was about 
$5 \mathrm{~g} / \mathrm{cm}^{2}$ of electrode/day which is an order of magnitude higher than other graphene producing methods, such as CVD and low temperature exfoliation.

Graphene has some remarkable properties including high ballistic electron mobility, high thermal and electrical conductivity which may allow the material to be used in electrochemical capacitors [27 -29] and anodes and cathodes in lithium ion batteries [30], electrodes for fuel cells [31] and many other applications [32]. Existing

methods for the production of graphene are based upon chemical oxidation of graphite [33], exfoliation of graphite in organic solvents [34], chemical vapour deposition [35 37] and molten metals [38]. Compared to the molten salt intercalation route, most of the other processes operate at very low production rates.

\section{Synthesis of nanodiamonds}

It has been shown by theoretical analysis that $\mathrm{sp}^{3}$ diamond nucleation from $\mathrm{sp}^{2}$ carbon is possible inside carbon nanotubes or nanoparticles due to surface tension effects [39] and there have been many attempts to convert carbon nanotubes to diamonds using plasma techniques, laser irradiation, shock waves and plasma sintering [40-42] but all these techniques require very high pressures and temperatures as well as metallic catalysts. Non-metallic catalysts, such as alkali carbonates, have also been used although even higher temperatures and pressures are required as well as longer reaction times [43].

When electrolysing $\mathrm{LiCl}$ containing lithium oxide, the reaction at the anode is likely to be reaction of the oxygen ions with the carbon to give carbon dioxide which would be soluble in the melt and can react with the lithium oxide to form lithium carbonate [44]. Examination of the nanocarbon particles and nanoscrolls showed lithium carbonate nanoparticles incorporated into the structure between the graphene layers 
(Figure 8) [44]. As mentioned above, lithium carbonate is a known catalyst for the conversion of graphite to diamond, albeit at very high temperatures and pressures and, even then, it takes several hours for the diamonds to form.

The oxidation of the carbon nanostructures produced in molten $\mathrm{LiCl}$ proceeds at considerably lower temperatures than those typically needed for the oxidation of carbon nanomaterials, due to the catalytic effect of lithium carbonate crystals encapsulated in graphitic nanostructures [45]. It was found that when the carbon nanoparticles, containing lithium carbonate were heated in air at about $500^{\circ} \mathrm{C}$, the nanoparticles were converted into octahedral nanodiamonds (5nm- $1 \mu \mathrm{m})$ as shown in figure 9 [44]. Although the particles were ignited in air at $500^{\circ} \mathrm{C}$, it is likely that the true temperature is very much higher and probably closer to $4500^{\circ} \mathrm{C}$. The formation of nanodiamonds was confirmed by the diffraction pattern of the [111] plane of diamonds with additional evidence given by the Raman Spectra of the material which confirmed the existence of diamond. After the heat treatment it was found that the density increased from $2.2 \mathrm{gcm}^{-3}$ to $3.0 \mathrm{gcm}^{-3}$ which is in accordance with the transformation of diamonds form graphite.

Nanodiamonds are usually made by taking diamonds that have been made at very high temperatures and pressures followed by grinding to create nanodiamonds. However, the shapes of the nanodiamonds are no way as perfect as those found by the molten salt precursor route. The properties of these novel perfect diamonds, shown in Figure 8, prepared by this electrochemical molten salt route are, at present, being determined.

\section{Overview of the molten salt synthesis of nanocarbons}


As described earlier, molten salts have been used for decades for the industrial production of aluminium, magnesium, sodium and lithium. By far the largest production is for aluminium at around 50 million tonnes/year. For each tonne of aluminium that is produced, about 0.4 tonne of carbon is consumed. The Hall-Heroult cells for aluminium operate at about $4 \mathrm{~V}$ with a current density of around $1 \mathrm{~A} / \mathrm{cm}^{2}$. The temperature of the cells is around $950^{\circ} \mathrm{C}$ and, somewhat surprisingly, the aluminium product is sold for about $\$ 3 / \mathrm{kg}$ which can be compared with nanoparticles and nanodiamonds which sell for \$3/g. The technology described in this paper where the temperature is around $800^{\circ} \mathrm{C}$, the voltages are of the order of $4 \mathrm{~V}$ and the current density is about $1 \mathrm{~A} / \mathrm{cm}^{2}$ are very similar to that of the Hall-Heroult cell. Given that the quantity of carbon consumed is about the same, this indicates that carbon nanoproducts could be made for an order of magnitude smaller cost than at present! This applies to nanotubes, graphene and nanodiamonds. As the erosion of the graphite rod electrodes was very uniform one can envisage that planar electrodes could be used, perhaps of $1 \mathrm{~m}^{2}$ dimensions so a unit, with about 20 graphite plates, about $1 \mathrm{~m}^{3}$ in size could produce about $600 \mathrm{~kg} /$ day or 4 tonnes/week or 200 tonnes/year which is much higher production rate than other methods for nanoparticles. Furthermore, it is also very interesting to note that in the western world there are plenty of redundant Hall-Heroult cells as much of the aluminium industry has moved from Europe to regions of the world where energy costs are significantly lower [46].

\section{Conclusions}

Carbon is basically a very cheap commodity and is used industrially on an enormous scale. However, as the size of the carbon product goes from $\mathrm{cm}$ scale to nanoscale, the cost increases very significantly. This paper demonstrates that by using molten 
salts, electrochemistry and technology that is readily available from the metallurgical industry, it should be possible to reduce the cost of carbon nanoproducts such as nanoscrolls, nanoparticles, nanodiamonds and graphene considerably. Although the basic electrochemistry has been proven but there is still much to do to convert a successful laboratory experiments into an industrial processes.

\section{Conflict of interests}

The University of Cambridge has licensed the technology for the manufacture of nanodiamonds and graphene to two separate companies.

\section{References}

1. Handbook of Extractive Metallurgy, Ed Habashi F., Wiley-VCH, Weinheim,1977

2. Thonstad J, Fellner P, Haarberg GM, Hives J, Kvande H, Sterten A (2001) Aluminium Electrolysis; Fundamentals of the Hall-Heroult process. Aluminium-Verlag, Dusseldorf

3. Mikhalev Y, Oye HA (1996) Absorption of metallic sodium in cathode carbon materials. Carbon 34:37-41

4. Joseph TB, Sanil N, Mohandas KS, Nagarajan K (2015) Study of graphite as anode in the electro-deoxidation of solid $\mathrm{UO} 2$ in $\mathrm{LiCl}-\mathrm{Li}_{2} \mathrm{O}$ melt. $\mathrm{J}$. Electrochem. Soc 162:E51-E58

5. Pal'yanov YN, Sokol AG, Borzdov YN, Khokhryakov AF, Sobolev NV (1999) Diamond formation from mantle carbonate fluids. Nature 400:417-418 
6. Kamali AR, Divitini G, Schwandt C, Fray DJ (2012) Correlation between microstructure and thermokinetic characteristics of electrolytic carbon nanomaterials. Corros Sci 64:90-97

7. Kamali AR, Fray DJ (2013) Molten salt corrosion of graphite as a possible way to make carbon nanostructures. Carbon 56:121-136

8. He Z, Gao L, Wang X, Zhang B, Qi W, Song J, et al. (2014) Improvement of stacking order in graphite by molten fluoride salt infiltration. Carbon; 72:304311

9. Pal'yanov YN, Kupriyanov IN, Khokhryakov AF ,Ralchenko VG (2015) Crystal Growth of Diamond, Handbook of Crystal Growth: Bulk Crystal Growth (Second Edition), Elsevier, 671-713

10. Tomlinson E, Jones A, Milledge J (2004) High-pressure experimental growth of diamond using $\mathrm{C}-\mathrm{K}_{2} \mathrm{CO}_{3}-\mathrm{KCl}$ as an analogue for Cl-bearing carbonate fluid, Lithos 77: 287-294

11. Hsu WK, Terrones M, Hare JP, Terrones H, Kroto HW, Walton DRM (1996) Electrolytic formation of carbon structures. Chem Phys Lett 262:161-16

12. Chen GZ, Fan X, Luget A, Shaffer MSP, Fray DJ, Windle AH (1998) Electrolytic conversion of graphite to carbon nanotubes in molten salts. J Electroanal Chem 446(1-2):1-6

13. Hsu WK, Li J,Terrones H, Terrones M, Grobert N, Zhu YQ, Trasobares S, Hare JP, Pickett CJ, Kroto HW, Walton DRM (1999) Electrochemical production of low melting metal nanowires. Chem Phys Lett 301:159-166

14. Schwandt C, Dimitrov AT, Fray DJ (2010) The preparation of nano-structured carbon materials by electrolysis of molten lithium chloride at graphite electrodes. J Electroanal Chem 647:150-158 
15. Kamali AR, Schwandt C, Fray DJ (2011) Effect of the graphite electrode material on the characteristics of molten salt electrolytically produced carbon nanomaterials. Mater Charact 62:987-994

16. Kamali AR, Fray DJ (2014) Towards large scale preparation of carbon nanostructures in molten LiCl, Carbon 77: 835-84Cl.

17. Kinloch IA, Chen GZ, Howes J, Boothroyd C, Singh C, Fray DJ, Windle AH (2003) Electrolytic, TEM and Raman studies on the production of carbon nanotubes in molten NaCl. Carbon 41:1127-1141

18. Thackeray MM (1995) Structural considerations of layered and spinel lithiated oxides for lithium ion batteries. J. Electrochem. Soc. 142:2558-2563

19. Zavalis TG, Behm M, Lindbergh G. (2012) Investigation of short circuit scenarios in lithium ion battery cell. J. Electrochem.Soc, 159: A848-A859

20. Tarascon JM, Guyomard D (1991) Lithium metal free rechargeable batteries based upon $\mathrm{Li}_{1+x} \mathrm{Mn}_{2} \mathrm{O}_{4}$ cathodes and carbon anodes. J.Electrochem. Soc. 38: 2864-2868

21. Winter M, Besenhard JO (1999) Electrochemical lithiation of tin and tin-based intermetallics and compounds. Electrochem.Acta 145:31-50

22. Das Gupta R, Schwandt C, Fray DJ (2014) Preparation of tin filled carbon nanotubes and nanoparticles by molten salt electrolysis. Carbon 70:142-148

23. Das Gupta R (2009) The electrochemical production of tin filled carbon nanotubes and their use as anode materials in lithium-ion batteries. Ph.D. Thesis, University of Cambridge.

24. Kamali AR, Fray DJ, Unpublished results.

25. Kamali AR, Fray DJ (2015) A possible scalable method for the synthesis of Sn-containing carbon nanostructures, Mater Today Commun 2: 38-48 
26. Kamali AR, Fray DJ (2015) Large-scale preparation of graphene by high temperature insertion of hydrogen in graphite ,Nanoscale 7:11310-11320

27. Hou L, Lian L, Li D, Pang G, Li J, Zhang X, Xiong S, Yuan C (2013) Mesoporous N-containing carbon nanosheets towards high performance electrochemical capacitors. Carbon 64:141-149

28. Chen JC, Liu YQ, Li N, Wu C, Xu L, Yang H (2015) Nanostructured polystyrene/polyaniline/graphene hybrid materials for electrochemical supercapacitor and Na-ion battery applications. J. Mat. Sci 50:5466-5474

29. Xian HY, PengTJ, Sun HJ, Wang JD (2015) Preparation of graphene nanosheets from microcrystalline graphite by low-temperature exfoliated method and their supercapacitive behavior. J. Mat Sci 50:4025-4033

30. Wang G, Shen X, Yao J, Park J (2009) Graphene nanosheets for enhanced lithium storage in lithium ion batteries. Carbon 47:2049-2053

31. Wang Z, Shoji M, Ogata H (2012) Synthesis and characterisation of platinium nanoparticles on carbon nanosheets with enhanced electrocatalytic activity toward methanol oxidation. App Surf Sci 259:219-224

32. Li X, Wang X, Zhang L, Lee S, Dai H (2008) Chemically derived ultrasmooth graphene nanoribbon semiconductors. Science 319:1229-1232

33. Li D, Müller MB, Gilje S, Kaner RB, Wallace GG (2008) Processable aqueous dispersions of graphene nanosheets. Nature Nanotechnology 3:101-105

34. Nicolosi V, Chhowalla M, Kanatzidis MG, Strano MS, Coleman JN (2013) Liquid exfoliation of layered materials. Science 340:1420

35. Malesevic A, Vizireanu S, Kemps R, Vanhulsel A, Haesendonck CV, Dinescu G, (2007) Combined growth of carbon nanotubes and carbon 
nanowalls by plasma-enhanced chemical vapour deposition. Carbon 45:29322937

36. .Tanaike O, Kitada N, Yoshimura H, Hatori H, Kojima K, Tachibana M (2009) Lithium insertion behaviour of carbon nanowalls by dc plasma CVD and its heat -treatment effect. Solid State Ionics 180:381-385

37. Mori S, Veno T, Suzuki M (2011) Synthesis of carbon nanowalls by plasmaenhanced vapour deposition in a $\mathrm{CO} / \mathrm{H}_{2}$ microwave discharge system. Diamond and Related Materials 20:1129-113215

38. Shaahin A, Kalaantari H, Garey J, Balandin AA, Abbaschian R (2011) Growth of graphene and graphite nanocrystals from a molten phase. J. Mat. Sci 46:6255-6263

39. Liu QX, Wang CX, Li SW, Zhang JX, Yang GW (2004) Nucleation stability of diamond nanowires inside carbon nanotubes: A thermodynamic approach. Carbon 42: 629-633

40. Zhu YQ, Sekine T,Kobayashi T, Takazawa E, Terrones M, Terrones H (1998) Collapsing carbon nanotubes and diamond formation under shockwaves. Chem Phys Lett 287:689-693

41. Zhang F, Ahmed F, Holzhüter G, Burkel E (2012) Growth of diamond from fullerene C60 by spark plasma sintering. J Cryst Growth 340:1-5

42. Yusa H. (2002) Nanocrystalline diamond directly transformed from carbon nanotubes under high pressure. Diamond Related Mat 11:87-91

43. Pal'yanov YN, Sokol AG, Borzdov YM, Khokhryakov AF, Shatsky AF, Sobolev NV (1999) The diamond growth from $\mathrm{Li}_{2} \mathrm{CO}_{3}, \mathrm{Na}_{2} \mathrm{CO}_{3}, \mathrm{~K}_{2} \mathrm{CO}_{3}$ and $\mathrm{Cs}_{2} \mathrm{CO}_{3}$ solvent at $\mathrm{P}=7 \mathrm{GPa}$ and $\mathrm{T}=1700-1750^{\circ} \mathrm{C}$. Diamond Related Mat 8:1118-1124 
44. Kamali AR, Fray DJ (2015) Preparation of nanodiamonds from carbon nanoparticles at atmospheric pressure, Chem Comm 51:5594-5597

45. Kamali AR, Schwandt C, Fray DJ (2012) On the oxidation of electrolytic carbon nanomaterials. Corros Sci 54:307-13

46. House of Commons Environmental Audit Committee, Fourth Report of Session 2009-2010 The role of carbon materials in preventing dangerous climate change. The Stationary Office 2010

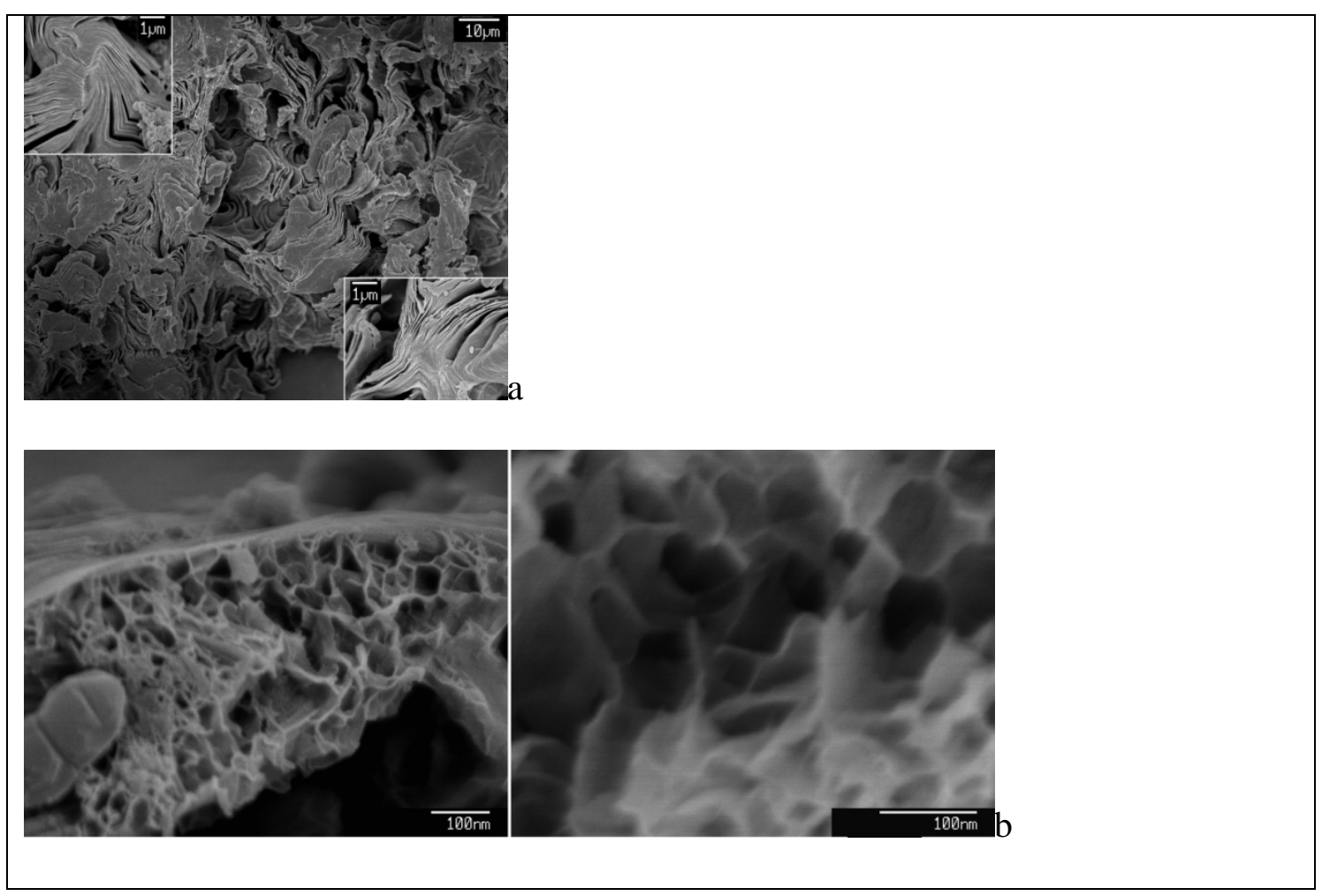




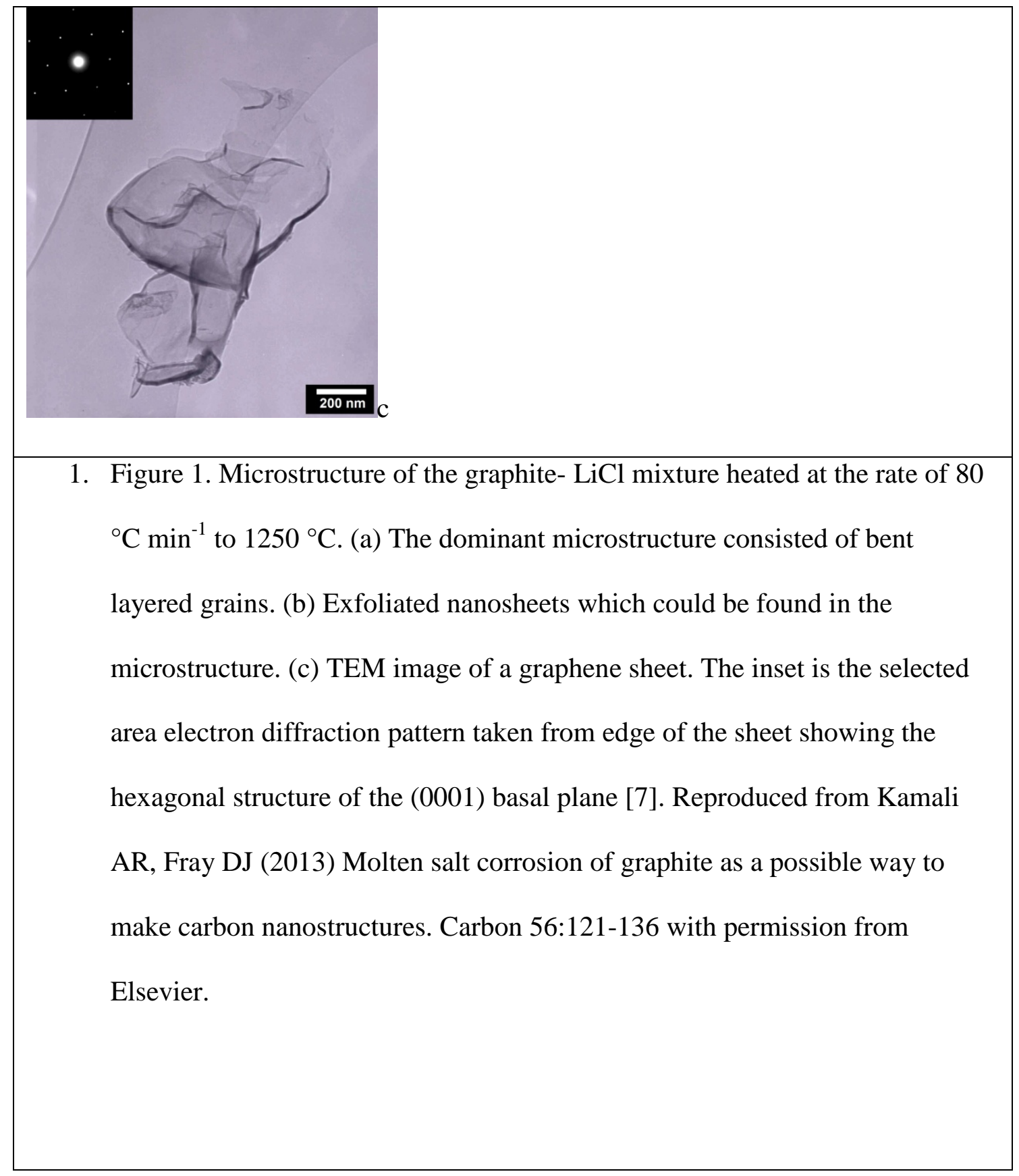

Figure 2. Schematic of the experimental set-up used for the small scale preparation of carbon nanostructures in molten $\mathrm{LiCl}$. A graphite rod is used as the cathode and a graphite crucible as the anode. A molybdenum wire is used as the quasi-reference electrode [14]. Reproduced from Schwandt C, Dimitrov AT, Fray DJ (2010) The preparation of nano-structured carbon materials by 
electrolysis of molten lithium chloride at graphite electrodes. J Electroanal Chem 647:150-158 with permission from Elsevier.

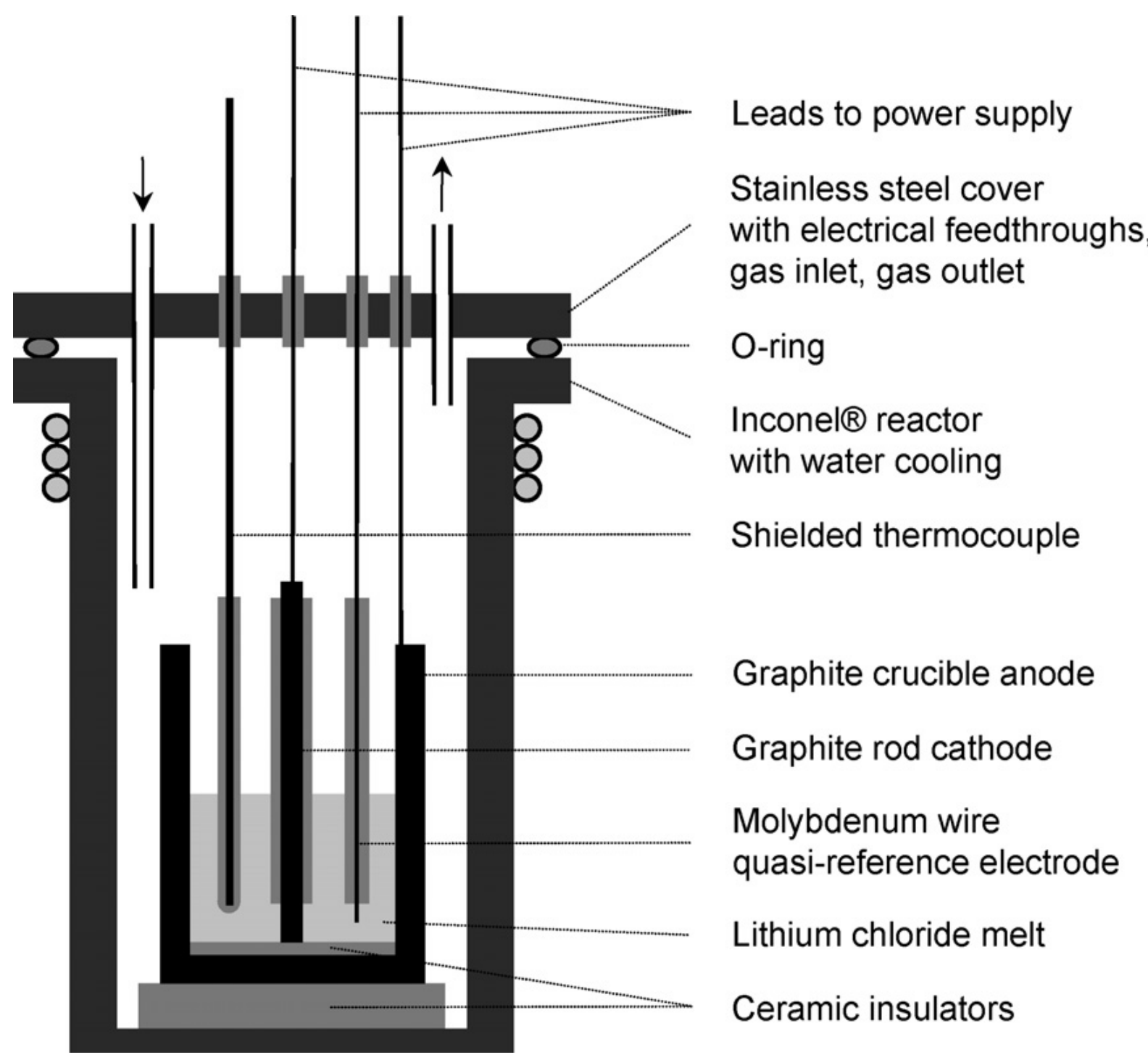




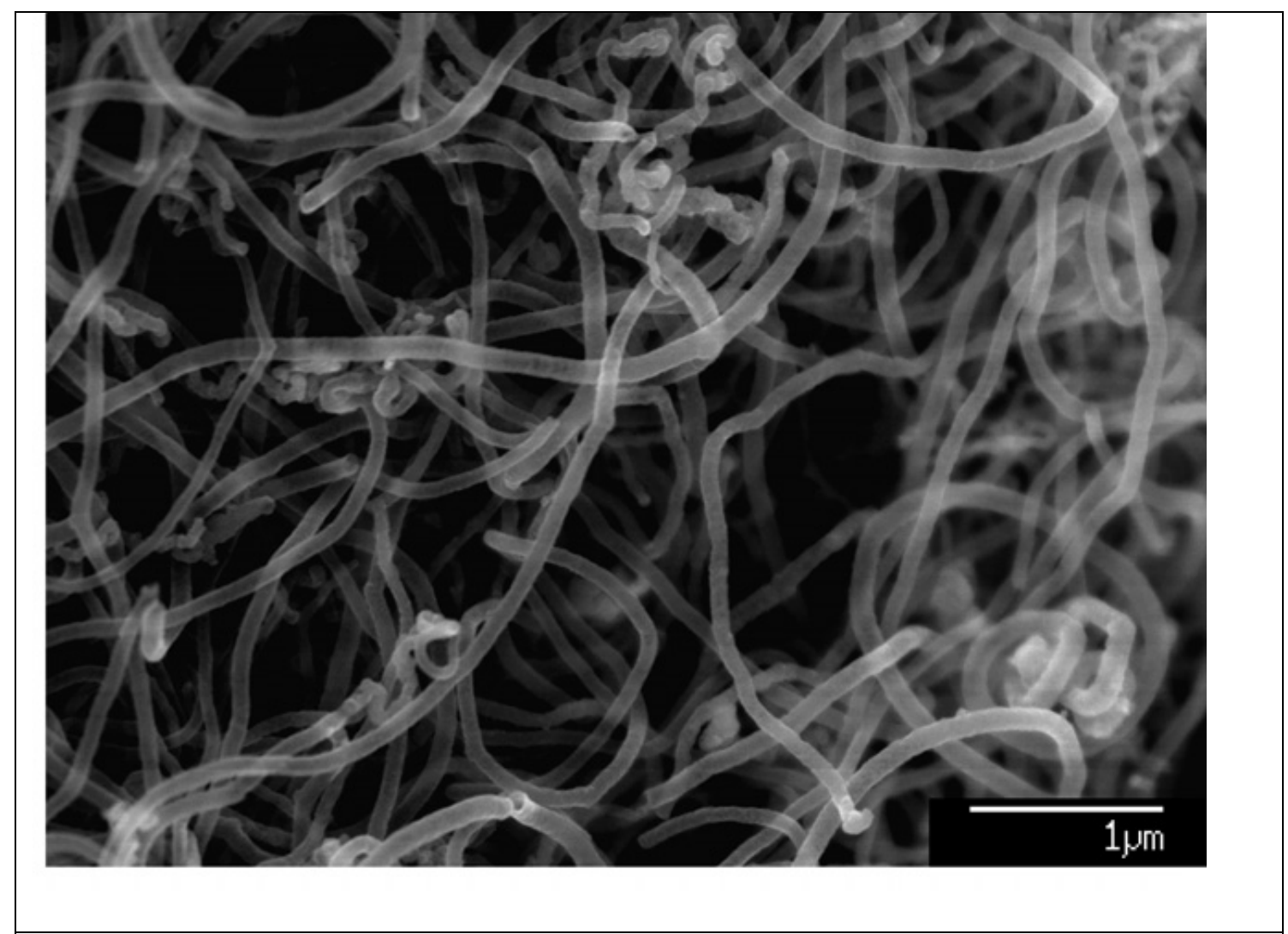

Figure 3. Scanning electron microscopic image of a carbonaceous product that contains nanotubes as the main constituent. Experimental was conducted at temperature $775^{\circ} \mathrm{C}[14]$.

Reproduced from Schwandt C, Dimitrov AT, Fray DJ (2010) The preparation of nanostructured carbon materials by electrolysis of molten lithium chloride at graphite electrodes. J Electroanal Chem 647:150-158 with permission of Elsevier. 


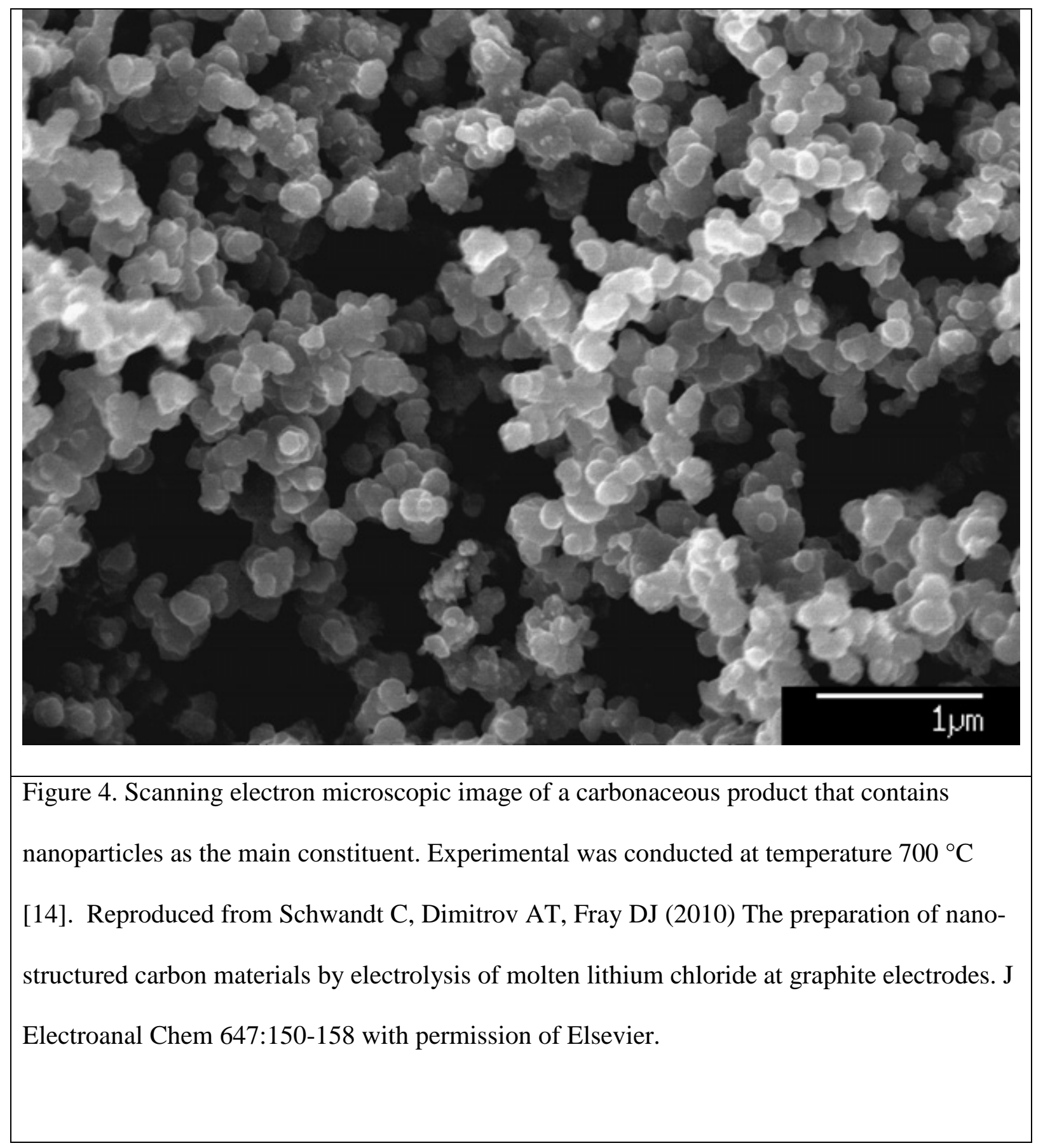




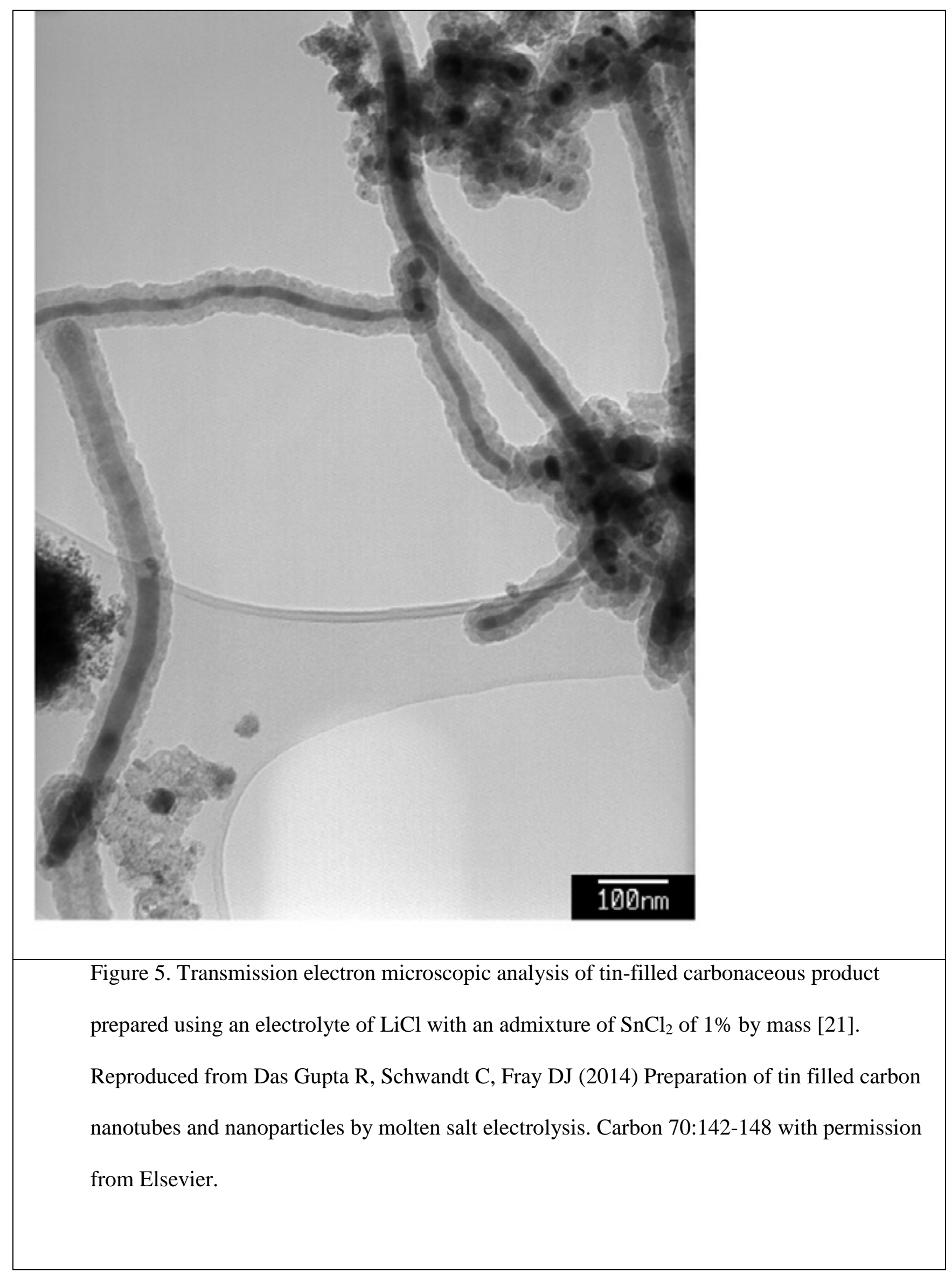




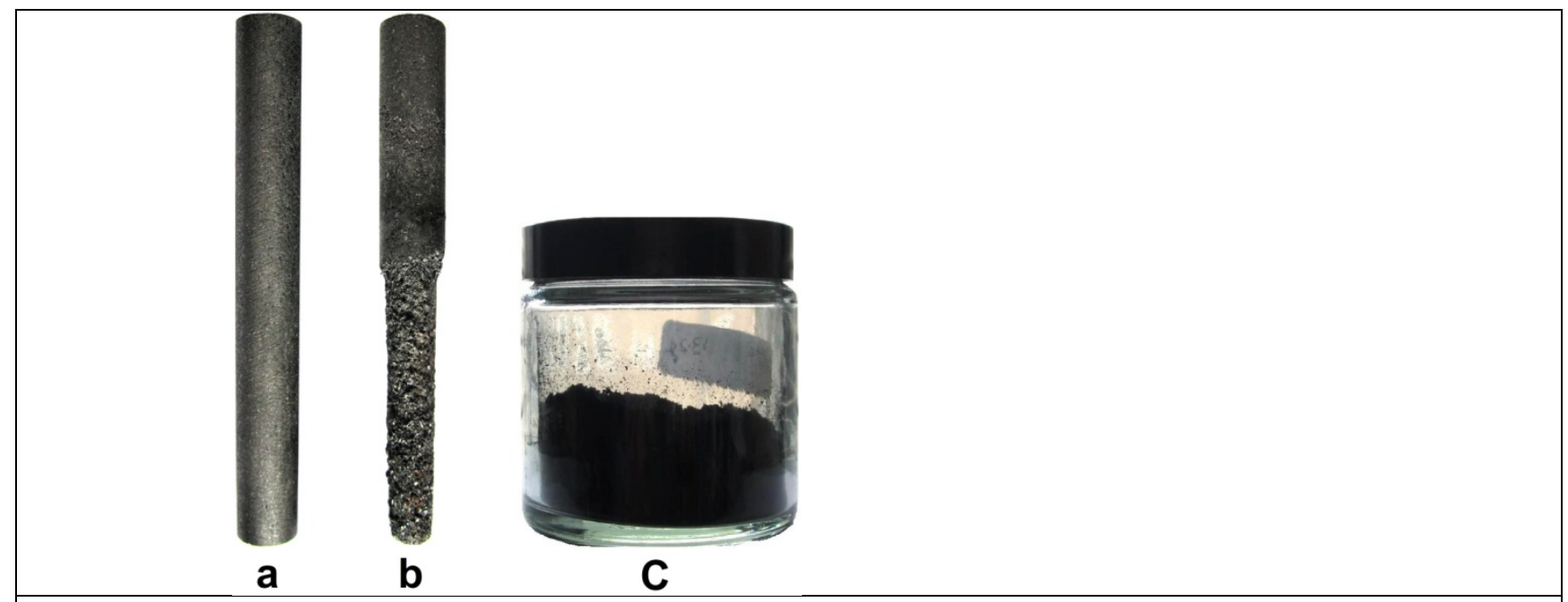

Figure 6. The photographs of (a) the graphite rod which was used as cathode in the molten

salt process conducted under moist gas flow, (b) the graphite cathode after the molten salt process, and (c) the graphene product stored in a jar [25] . Reproduced from Kamali AR, Fray DJ (2015) Large-scale preparation of graphene by high temperature insertion of hydrogen in graphite ,Nanoscale, 10.1039/C5NR01132A with permission from the Royal Society of Chemistry.
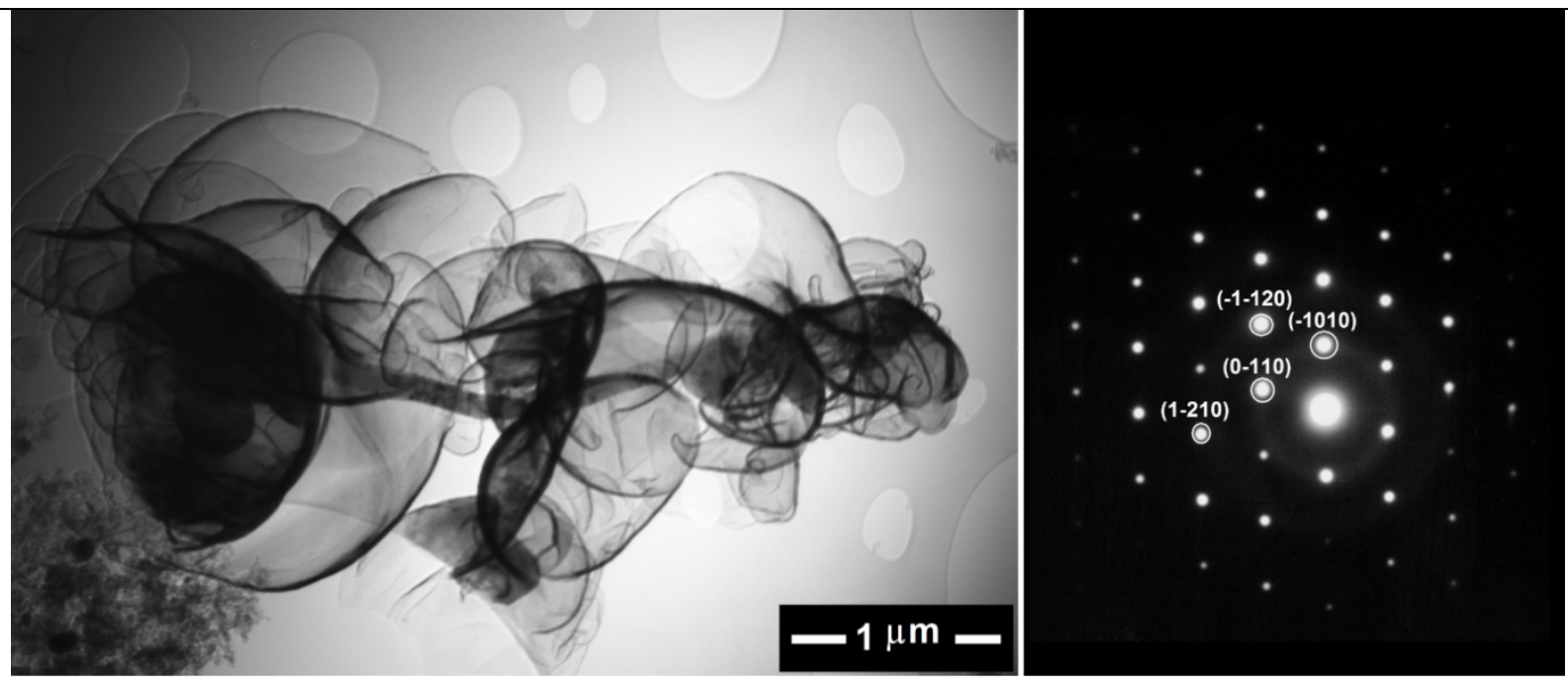

Figure 7. TEM micrograph of the graphene nanosheets produced as well a typical electron diffraction pattern recorded at relatively flat edge of a graphene sheet, with the peaks labelled by Miller-Bravais indices[25]. Reproduced from Kamali AR, Fray DJ (2015) Large-scale 
preparation of graphene by high temperature insertion of hydrogen in graphite ,Nanoscale, 10.1039/C5NR01132A with permission from the Royal Society of Chemistry.

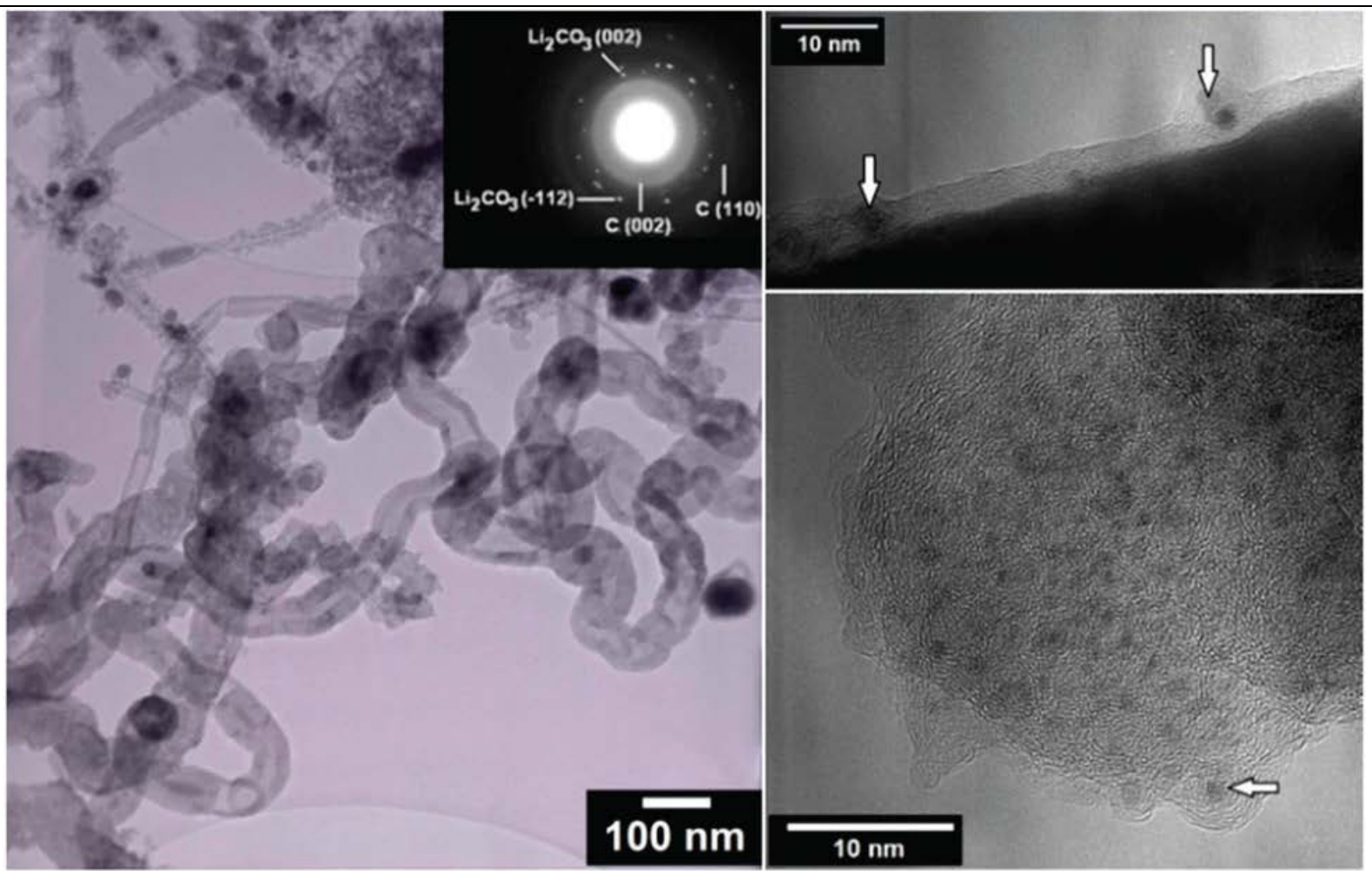

Figure 8. TEM micrograph of the as-synthesized electrolytic carbon material. The right panel shows a number of CNTs, and the inset is a typical selected area diffraction pattern confirming the presence of graphitic carbon and Li2CO3 single-crystals. The left panel exhibits two high resolution TEM image. The upper image shows a wall of a CNT demonstrating that Li2CO3 nanocrystals, pointed by arrows, embedded into the graphitic structure of the wall. The down image presents a carbon nanoparticle in which Li2CO3 nanocrystals are encapsulated in carbon shells [40]. Reproduced from Kamali AR, Fray DJ (2015) Preparation of nanodiamonds from carbon nanoparticles at atmospheric pressure, Chem Comm 51:5594-5597 with permission of the Royal Society of Chemistry. 


Figure 9. SEM micrographs of the ECM after heat treatment in air showing nano and micron
sized diamonds. The left hand panel shows diamond crystal which are growing on a carbon
substrate [40]. Kamali AR, Fray DJ (2015) Preparation of nanodiamonds from carbon
nanoparticles at atmospheric pressure, Chem Comm 51:5594-5597

